\title{
On-Line Control of 1ph. She-Pwm Voltage Source Inverter for Statcom Applications
}

\author{
N. G. Apte ${ }^{1}$, Dr. V. N. Bapat ${ }^{2}$, V. S. Jagdale ${ }^{3}$, and N. I. Dhang ${ }^{4}$ \\ ${ }^{1}$ Lecturer in Electrical Engineering, Walchand College of Engineering, Sangli, India. \\ ${ }^{2}$ Principal, College of Engineering, Miraj, India. \\ ${ }^{3}$ CEO, Shreem Capacitors Pvt. Ltd., Kolhapur, India. \\ ${ }^{4}$ Assistant Manager, R\&D Department, Shreem Capacitors Pvt. Ltd., Kolhapur, India. \\ ngapte@rediffmail.com, vbkanhaji@gamil.com, \\ vikas@shreemcapacitors.com nagesh@shreemcapacitors.com
}

\begin{abstract}
On-line solution of switching angles of Selective Harmonic Elimination (SHE) PWM inverter has been a subject of research since 70s. Recent research has suggested new online control techniques for microprocessor implementation of SHE PWM method such as regular sampled harmonic elimination, space vector techniques, Walsh function harmonic elimination. A method based on curve fitting has been proposed in this paper. The solution trajectories by Newton iteration method are approximately represented by using $7^{\text {th }}$ order polynomial. On-line computation of switching angle $(\alpha)$ is just evaluation of polynomial equation by substituting value of modulation index $(m)$. The complete solutions for unipolar switching pattern to eliminate 3rd to 23rd harmonics in the VSI output using conventional technique and curve fitting technique has been given. The deviations of actual and approximate solutions are also presented along with corroborative experimental results on a $1 \mathrm{ph}, 230 \mathrm{~V}$, 5kVA IGBT based VSI controlled by TMS320LF2406, 16-bit fixed point DSP processor.
\end{abstract}

Keywords: Selective Harmonic Elimination (SHE), Voltage Source Inverter (VSI), Modulation Index, On-line control, Curve fitting

\section{Introduction}

SHE PWM was originally proposed by Patel and Hoft [2]. The SHE PWM inverters eliminate low order harmonics and operate at low switching frequency that result in reduced switching losses [3]. The SHE-PWM output waveform obtained from H-Bridge VSI consists of series of positive and negative pulses of constant amplitude but variable switching instances as shown in Figure1. The waveform has $\mathrm{N}$ switching instances per quarter cycle to eliminate first (N-1) odd harmonics from the inverter output. The switching angles $\alpha_{1}, \alpha_{2}, \alpha_{3}, \ldots . . \alpha_{N}$ need to be calculated for given modulation index, m. The output waveform being odd symmetric dc and even harmonic components are equal to zero.

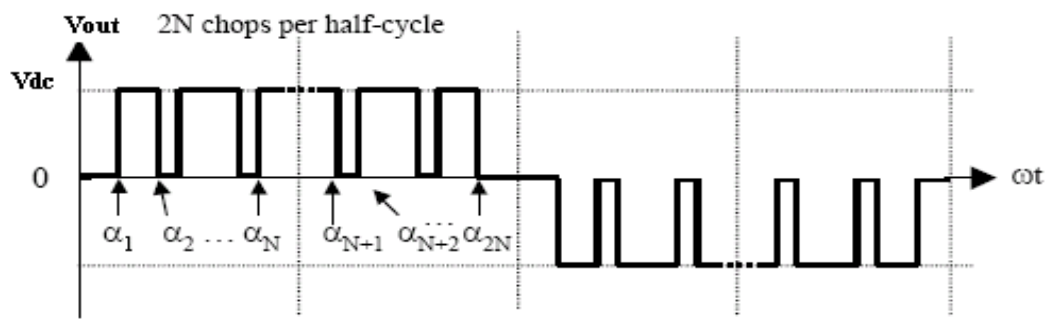

Figure 1. SHE PWM output waveform

Received: February 16,2010. Accepted: March 17, 2010 
The Fourier series of the three-level can be expressed as,

$$
V_{o}(\omega t)=\sum_{k=1}^{\infty} a_{k} \sin (k \omega t)
$$

where

$$
a_{k}=\frac{4 V_{d c}}{k \pi} \sum_{j=1}^{N}(-1)^{j+1} \cos \left(k \alpha_{j}\right)
$$

$\mathrm{k}$ is the harmonic order. $\mathrm{N}$ is the number of switching angles per quarter cycle. $\mathrm{V}_{\mathrm{dc}}$ is the amplitude of dc voltage source and $\alpha_{j}$ is the $\mathrm{j}^{\text {th }}$ switching angle which must satisfy the following condition

$$
\alpha_{1}<\alpha_{2}<\alpha_{3}<\ldots \alpha_{j} . .<\alpha_{N}<\frac{\pi}{2}
$$

From above, the non-linear SHE-PWM equations are,

$$
\begin{array}{lc}
\cos \left(\alpha_{1}\right)-\cos \left(\alpha_{2}\right)+\cos \left(\alpha_{3}\right) \ldots \ldots . . \pm \cos \left(\alpha_{N}\right)= & \frac{\pi}{4} m \\
\cos \left(3 \alpha_{1}\right)-\cos \left(3 \alpha_{2}\right)+\cos \left(3 \alpha_{3}\right) \ldots \ldots . \pm \cos \left(3 \alpha_{N}\right)= & 0 \\
\cos \left(5 \alpha_{1}\right)-\cos \left(5 \alpha_{2}\right)+\cos \left(5 \alpha_{3}\right) \ldots \ldots . . \pm \cos \left(5 \alpha_{N}\right)= & 0 \\
\cos \left(N \alpha_{1}\right)-\cos \left(N \alpha_{2}\right)+\cos \left(N \alpha_{3}\right) \ldots \ldots . \pm \cos \left(N \alpha_{N}\right)= & 0
\end{array}
$$

Where modulation index, $m=\frac{V_{o 1}}{V_{d c}}$

For given $m$, the nonlinear equations in (3) can be solved numerically using Newton iteration technique [2] to get $\alpha_{1}, \alpha_{2}, \alpha_{3}, \ldots . \alpha_{N}$. Typical solution trajectories are shown in Figure2. The solution process is math intensive and convergence largely depends upon choice of the initial values. This makes it unfit for microprocessor implementation. Various techniques for on-line solution of SHE equations are reported in [4] [5] [6]. A relatively simple method based on curve fitting is proposed in this paper which is described in subsequent sections.

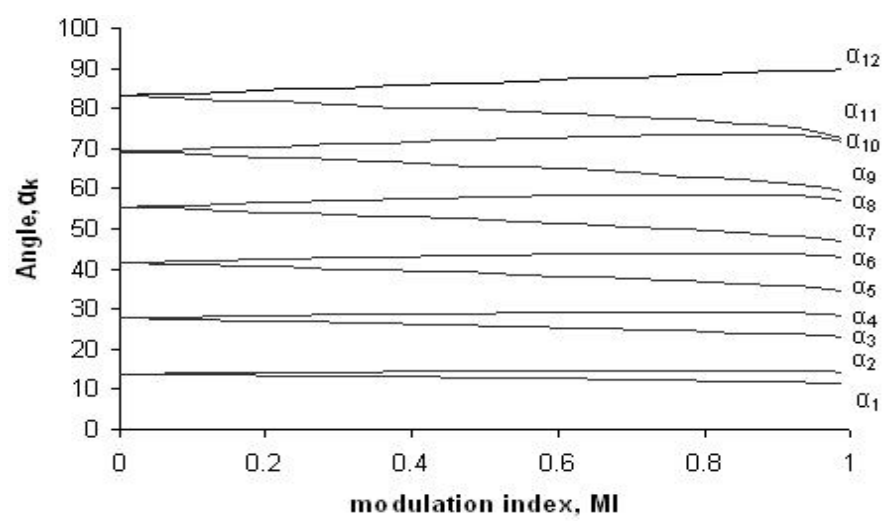

Figure 2. Typical solution trajectories of switching angles

\section{Online control of SHE VSI}

The approach taken here is to represent the solution trajectories with a polynomial equation in terms of $\mathrm{m}$. By using polynomial regression method [7], the approximate nth order polynomial can be expressed as,

$$
\alpha=C_{0}+C_{1} m+C_{2} m^{2}+\ldots . .+C_{n} m^{n}
$$


where $\mathrm{m}$ the polynomial order. The unknown coefficients $C_{0}, C_{1}, \ldots C_{n}$ are calculated using least square fit which minimizes the sum of squares of the deviations of the data which in this case is the values of $\alpha$ corresponding to each $m$, from (3). The order of the polynomial equations representing each trajectory is determined comparing residuals for various fits. In this work a $7^{\text {th }}$ order polynomial is used to represent the $\alpha$ trajectories. In the present work, the SHE inverter output has 12 switching instants that eliminate 3rd to 23rd harmonics from the inverter output. The values of $C_{0}$ to $C_{7}$ are given in the Table 1 for typical values of $\alpha_{1}, \alpha_{2}, \alpha_{3}$. Rests of the values are computed in the similar manner. The residual error for particular modulation index is shown in Figure3.

Table 1. SHE Polynomial constants

\begin{tabular}{|c|c|c|c|}
\hline & $\alpha_{1}$ & $\alpha_{2}$ & $\alpha_{3}$ \\
\hline$C_{0}$ & 13.8407 & 13.8476 & 27.6943 \\
\hline$C_{1}$ & -1.7945 & 1.4384 & -3.5137 \\
\hline$C_{2}$ & 1.8846 & 3.3679 & 4.2996 \\
\hline$C_{3}$ & -17.0898 & 27.5460 & 36.8583 \\
\hline$C_{4}$ & 55.8251 & 88.6621 & 119.9109 \\
\hline$C_{5}$ & -93.1147 & -147.890 & -199.930 \\
\hline$C_{6}$ & 76.8612 & 122.109 & 164.943 \\
\hline$C_{7}$ & -25.0164 & -39.777 & -53.6554 \\
\hline
\end{tabular}

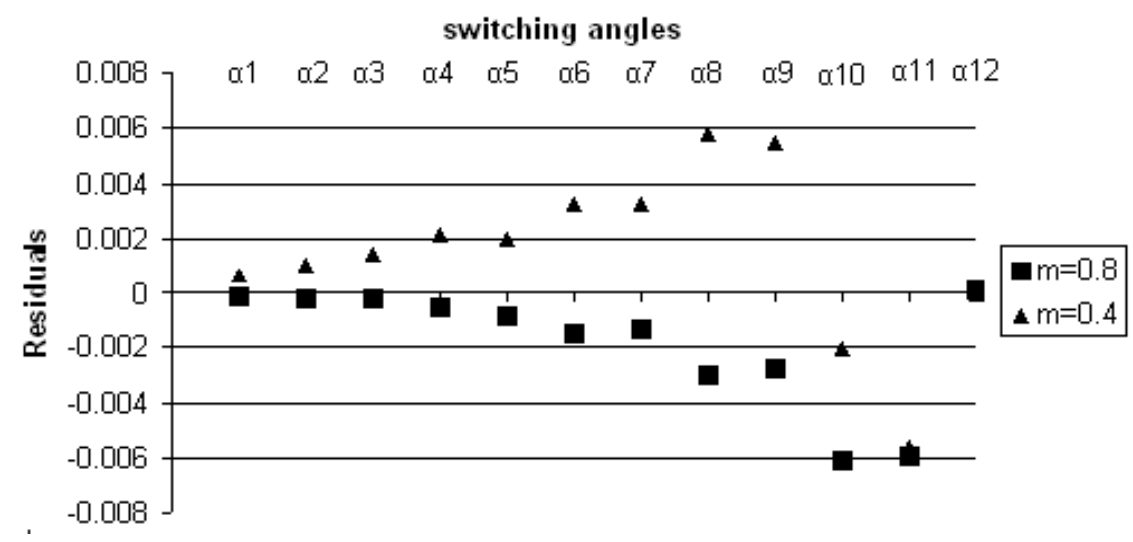

Figure 3. Residual error in $\alpha$ for $\mathrm{m}=0.8,0.4$

\section{Simulation Results}

The performance appraisal carried out by simulating 1ph. 425V, 80kVAR STATCOM being the end application of the proposed method of on-line control. The STATCOM has HBridge VSI as shown in Figure 4.

Various system parameters are listed in Table 2. The block diagram of the simulation is shown in Figure 5. The STATCOM considered here is a unit capacity of the parallel connected ones. The master controller decides target reactive power to be injected at PCC depending upon the demand. Each STATCOM unit has two control loops, DC bus voltage control loop and reactive power tracking loop [1]. DC bus voltage is maintained to $750 \mathrm{~V}$ by closed loop control of phase shift angle, $\delta$, between $V s$ and $V_{o I}$. Phase synchronization is by using a $1 \mathrm{ph}$. Phase Locked Loop. Reactive power tracking loop tracks the injected kVAR to a set value by on-line control of modulation index, $m$. 


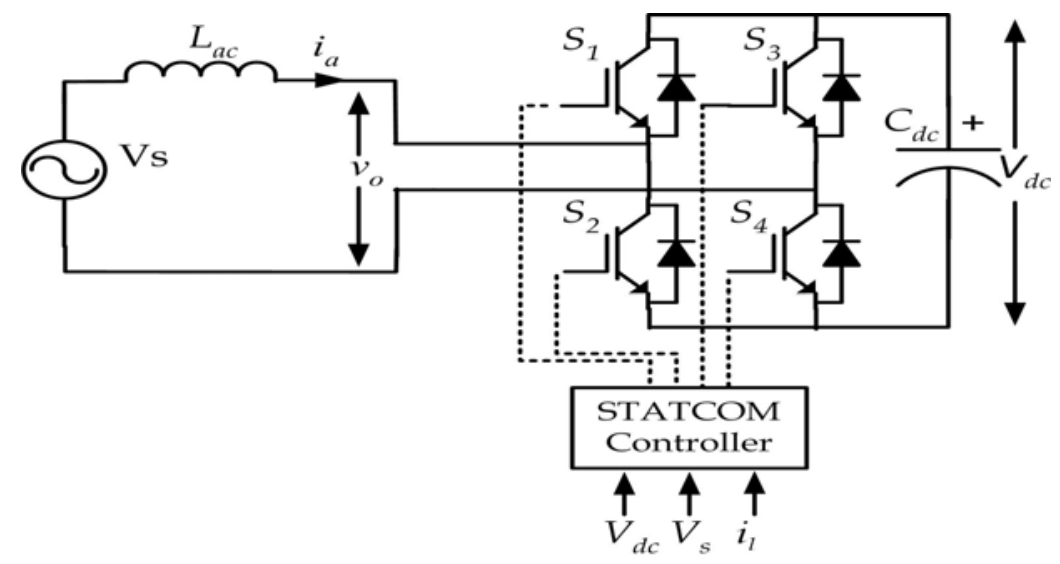

Figure 4. Block diagram of the H-Bridge VSI

The set value is sent by master controller. The VSI output is shown in Figure 6 and the coupling reactor current waveform is shown in Figure 7. The step response of the system is shown in Figure 8 which indicates that the response time is less than 3 power cycles.

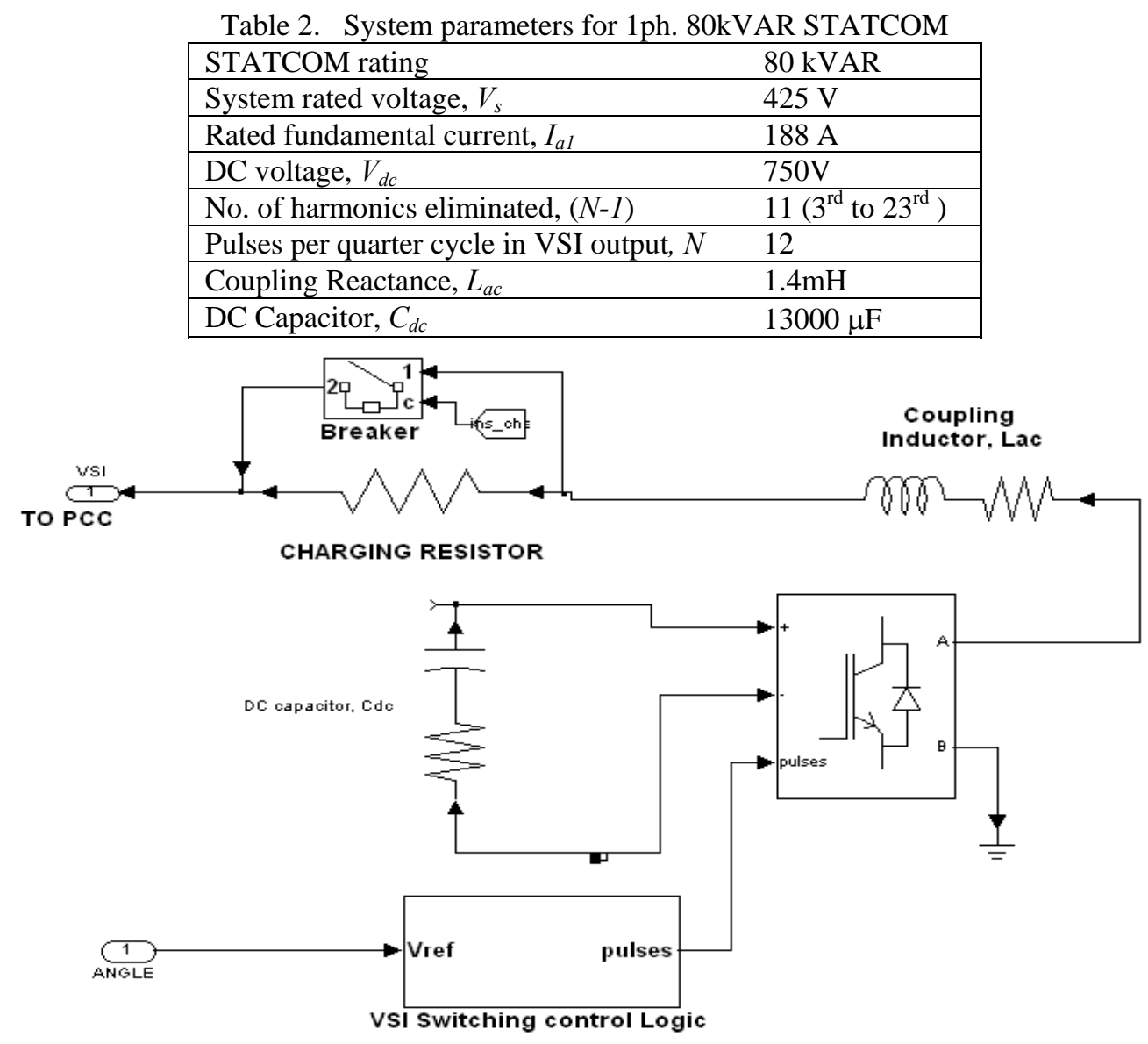

Figure 5. SIMULINK diagram of 80kVAR STATCOM 


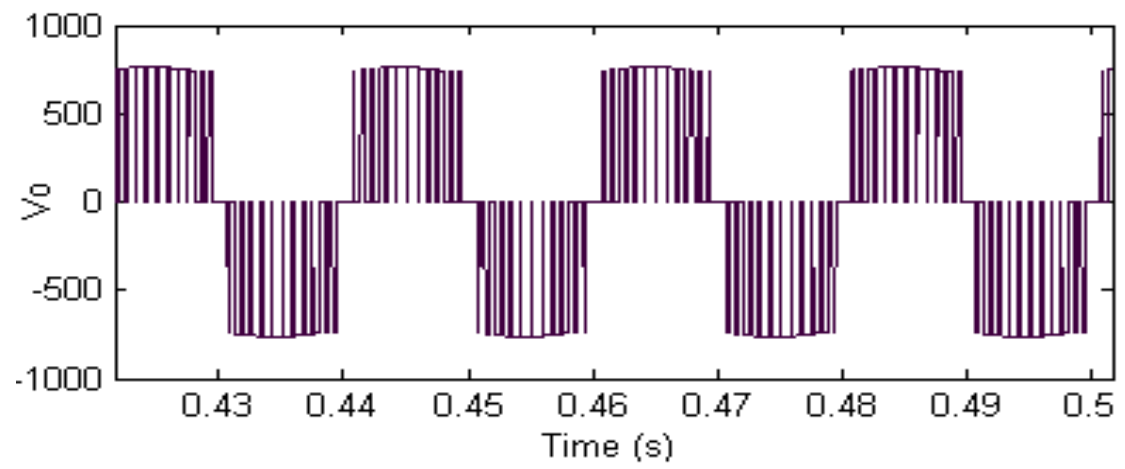

Figure 6. VSI output voltage, $V_{o}$ waveform

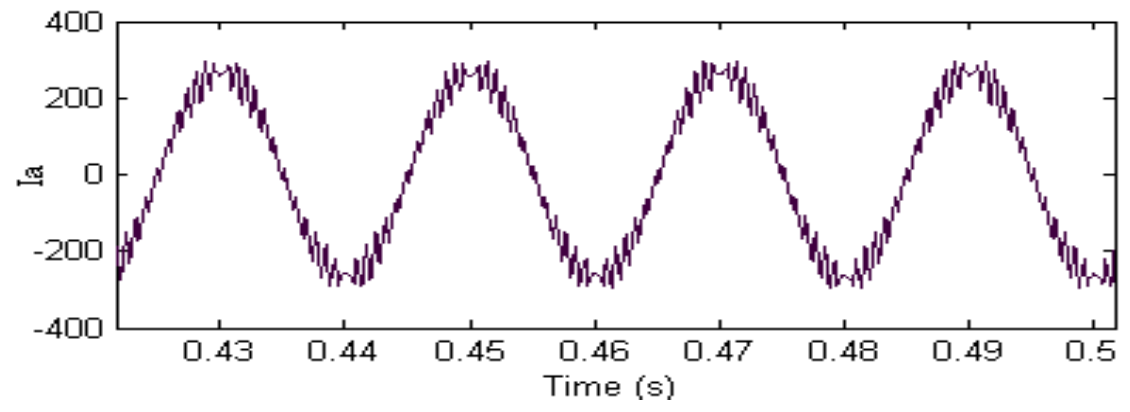

Figure 7. Coupling reactor current at rated conditions.

The simulated STATCOM operates in steady state by injecting 80kVAR. A step input of $80 \mathrm{kVAR}$ is given at $\mathrm{t}=0.4$. The response of the PCC voltage and injected current are shown in Figure 8. The response time is less than 3 cycles which confirms the efficacy of the proposed online SHE VSI control method.

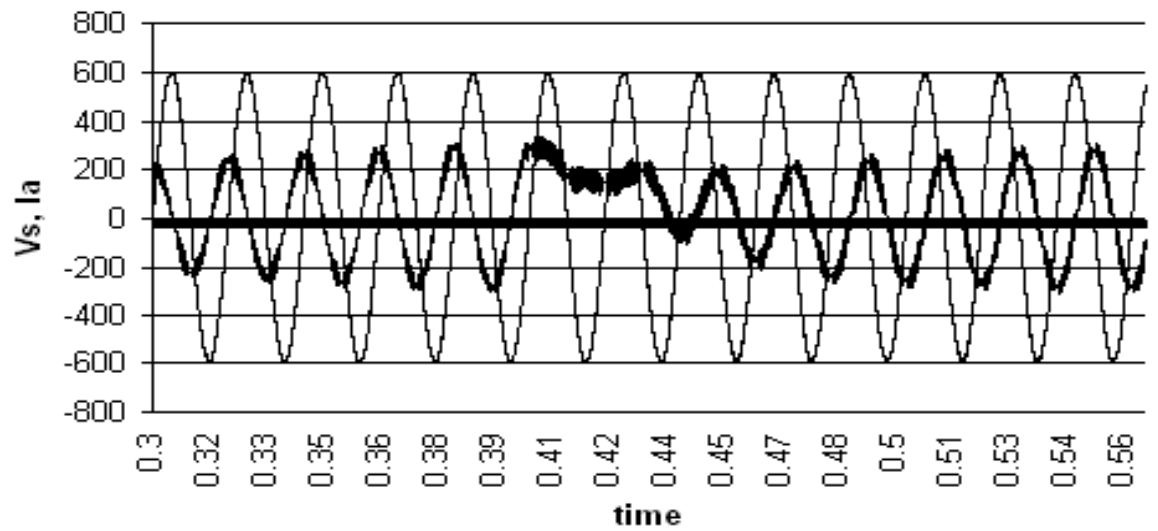

Figure 8. STATCOM response to step input. 


\section{Practical Implementation}

The online control method has been implemented on laboratory prototype of 230V, 5kVAR STATCOM. The practical system parameters are given in Table 3.

Table 3. Practical Parameters of 5kVAR STATCOM

\begin{tabular}{|ll|}
\hline STATCOM rating & $5 \mathrm{kVAR}$ \\
\hline System rated voltage, $V_{s}$ & $230 \mathrm{~V}$ \\
\hline Rated fundamental current, $I_{a I}$ & $22 \mathrm{~A}$ \\
\hline DC voltage, $V_{d c}$ & $400 \mathrm{~V}$ \\
\hline No. of harmonics eliminated, $(N-1)$ & $11\left(3^{\text {rd }}-23^{\text {rd }}\right)$ \\
\hline Pulses per quarter cycle in VSI output, $N$ & 12 \\
\hline Coupling Reactance, $L_{a c}$ & $1.8 \mathrm{mH}$ \\
\hline DC Capacitor, $C_{d c}$ & $11000 \mu \mathrm{F}$ \\
\hline
\end{tabular}

\subsection{Selection of passive parameters}

The selection of the two passive elements, $L_{a c}, C_{d c}$ is mainly constrained by harmonic distortion of the STATCOM injected current at PCC at rated conditions and dc bus voltage ripple respectively. The constraint on the TDD of the STATCOM injected current at PCC is less than $15 \%$ and the allowable ripple in the dc bus voltage is less than $5 \%$. The design formulae derived to calculate optimum values of $L_{a c}, C_{d c}$ are given as follows [8],

$$
\begin{aligned}
& X_{a c}=\frac{100}{T D D_{i}}\left\{\sum_{k=2}^{\infty}\left(\frac{4 V_{d c}}{k \pi} \sum_{j=1}^{N}(-1)^{j+1} \cos \left(k \alpha_{j}\right)\right)^{2}\right\}^{\frac{1}{2}} \\
& C_{d c}=\frac{m I_{a m}}{2 \omega \Delta V_{d c}}
\end{aligned}
$$

\subsection{Description of the hardware}

The on-line SHE VSI control logic is built around Texas instruments 16-bit DSP Processor TMS320LF2406. The device operates at 40MHz clock frequency. The SHE switching pulses and synchronising signal are generated with the help of two 16 bit timers (T3PWM and T4PWM). First timer generates SHE pulses and the other generates phase shifted logic signal synchronised with the PCC voltage.

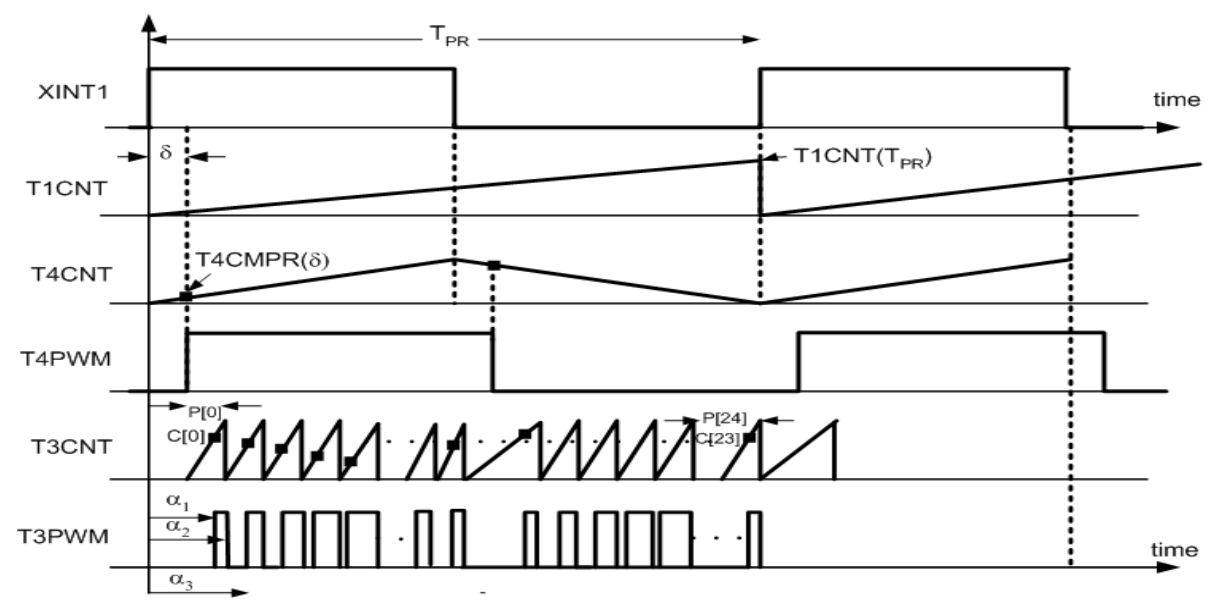

Figure 9. Timer output waveforms 
The reactive power control loop decides modulation index. Switching angles, $\alpha_{1}, \alpha_{2}, \ldots . . \alpha_{12}$ are calculated by solving polynomial equations by substituting modulation index. By measuring fundamental period (T1CNT), compare and period values (for T3PWM) for each $\alpha$ are calculated for every fundamental cycle. The compare and period values are stored in a 24 element array (12 switching angles in quarter cycle). The operation of various timers used for SHE pulse generation is shown in Figure 9.

The STATCOM performance at rated conditions is depicted in Figure 10 and Figure 11. The step response is shown in Figure 12. The response time is approximately 3-4 cycles which can be further improved by using a faster DSP.

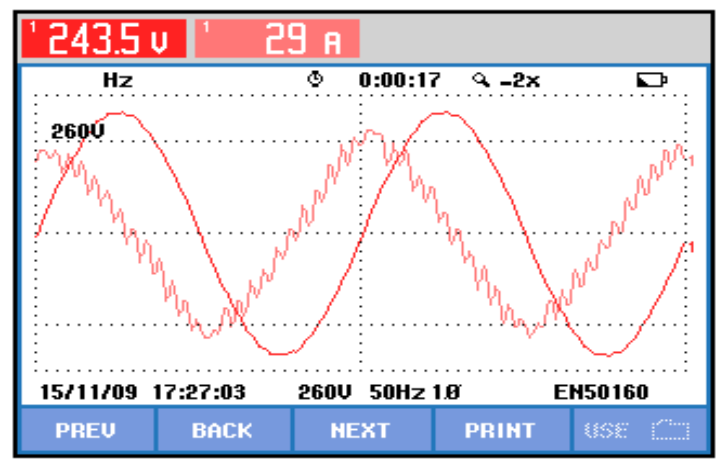

Figure 10. PCC Voltage and injected current at 5kVAR lead

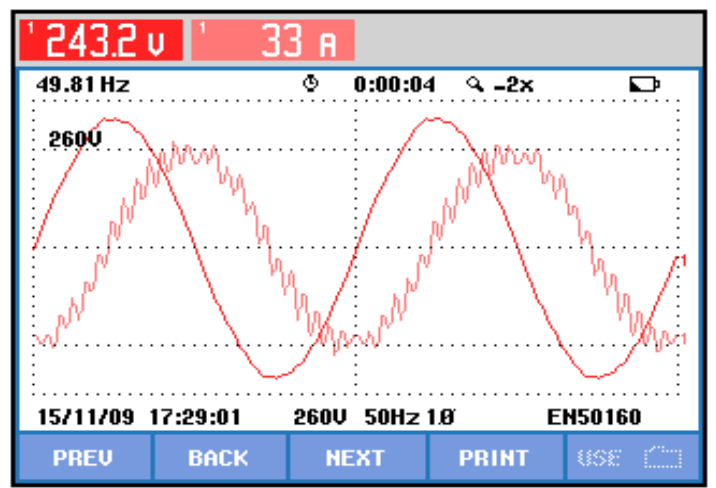

Figure 11. PCC Voltage and injected current at 5kVAR lag

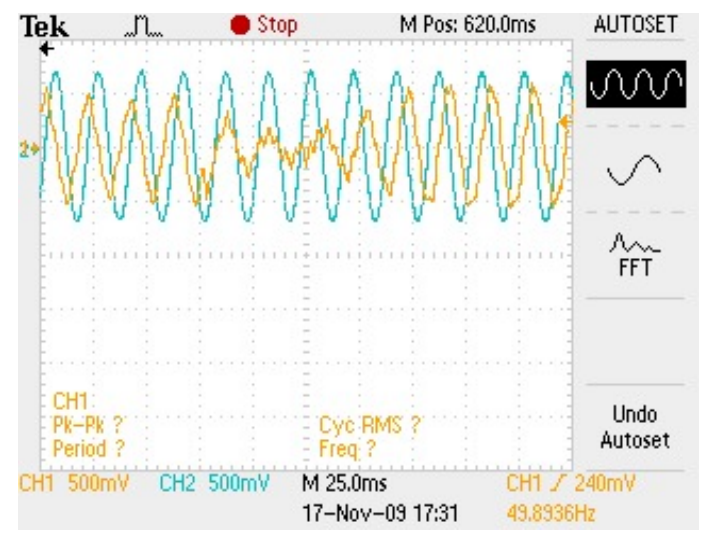

Figure 12. Step response of 5kVAR STATCOM 


\section{Conclusion}

The solution trajectories for solving SHE equations by conventional Newton iteration technique and curve fitting technique are in close agreement. The effectiveness of the method has been tested successfully both in simulation and hardware trial on a 5kVAR module. The step response time has been found to be less than 3 cycles. It could be further improved by using a processor of higher bit width and clock. Output frequency control is easily possible online adjustments of compare and period values timers used for SHE PWM.

\section{Acknowledgements}

Authors are sincerely thankful SHREEM Capacitors, Kolhapur, India for sponsoring the entire research work.

\section{References}

[1] N. Hingorani, L. Gyugyi, Understanding FACTS: Concepts and Technology of Flexible AC Transmission Systems. Piscataway, NJ: IEEE Press, 1999.

[2] H. Patel, R. Hoft, "Generalized technique of harmonic elimination and voltage control is thysristor inverters. Part I harminic elimination,” IEEE Trans. Industrial Applications, Vol IA-9, no. 3, pp 310-317, May-June 1973.

[3] P. Enjenti, P. Ziogas, J. Lindsay, "Programmed PWM techniques to eliminate harmonics-a critical evaluation,” IEEE Trans. On Industry Applications, Vol. 26, No.2, pp.302-315, March 1990.

[4] D. Czarkowski, D. chudnovsky, G. Chudnovsky, I. Selensnick, "Solving the optimal PWM roblem for Single-Phase Inverters", IEEE Trans. On Circuits and Systems-I: fundamental theory and applications, Vol. 49, No.4. pp. 465-475, April 2002.

[5] J. Chiasson, L. Tolbert, K. Mckenzie, Z. Du, “ A complete solution to harmonic elimination problem”, IEEE Transactions on Power Electronics, Vol. 19, No.2, pp. 491-499, March 2004.

[6] R. Jabr, "Solution trajectories of the harmonic elimination problem", Proc. IEE Electric Power Applications, Vol. 153, No.1, pp. 97-104, Jan. 2006.

[7] N. Azli, A.H.M. Yatim, "Curve fitting technique for optimal pulsewidth modulation (PWM)online control of a voltage source inverter (VSI)", in Proc. 2000, TENCON 2000, Vol. 1, pp. 419-422.

[8] J. Eknayake, N. Jenkins, "Selection of passive elements for three level inverter based static compensator,” IEEE Trans. On Power Delivery, Vol.14, No.2, pp. 665-661, April 1999.

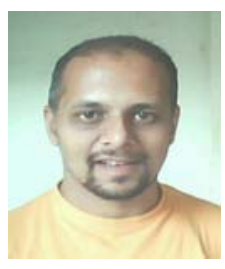

N. G. Apte, received B.E (Electrical) and M.E. (Electrical) in 1993 and 1995 respectively from Walchand College of Engineering, Sangli, India. He is working as senior lecturer in Electrical Engineering department for last 13 years. His areas of interest include embedded systems, power electronics applications to power systems.

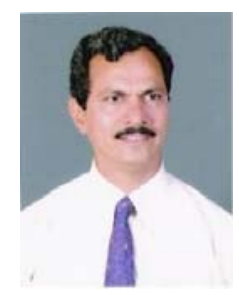

Dr. V. N. Bapat, received B.E. (Electrical) and M.E.(Electrical) 1983 and 1985 respectively from Walchand College of Engineering, Sangli, India. He received Ph.D. from Indian Institute of Technology in 1993. He has 25 years of teaching experience. Presently, he is working as Principal, College of Engineering, Miraj, India. His areas of interest are control systems, electrical machine design. 
V. S. Jagdale, received his B.E.(Electronics) in 1992. He has 18 years of administrative experience in H.T., LT capacitor manufacturing company. Presently, he is CEO of Shreem Electric Ltd., Kolhapur, India.

N. I Dhang, received B.E. and M.E.(Electrical) in 1996 and 1998 respectively. He is working as Asst. Manager, R\&D, Shreem Electric Ltd., Kolhapur, India. He has 12 years of industrial experience. His areas of interest are Automatic power factor controllers, Thyristor switched capacitor panels, installation of H.T. \& L.T. capacitor banks. 